\title{
Survey of emission reduction of greenhouse gas in asphalt mixture Yangning $^{1}$, ChengDongxiang ${ }^{2}$, Chenjin $^{3}$
}

(Nanjing Communications Institute of Technology, Nanjing, Jiangsu province, 211188)

\author{
Keywords: Warm mixed asphalt; Greenhouse gas; Methodology; Review
}

\begin{abstract}
Recent years, China has gradually begun to promote the development of asphalt pavement with low carbon and environmental protection features in the field of asphalt pavement construction. However, at present, our country has not formed the corresponding asphalt mixture greenhouse gas emission reduction calculation method. Based on the analysis of domestic and international literature, this paper puts forward five key problems, such as the research of energy consumption and greenhouse gas emissions of asphalt mixture, and the key problems to be solved.
\end{abstract}

\section{Introduction}

In recent years during the structure of China's highway network, the asphalt pavement has a great proportion in the highway because its advantages of comfortable, good visual effect, low noise, convenient maintenance and so on. However, large scale highway traffic construction has brought the environmental problems which can not be ignored. According to a foreign survey data, 3.5 tons of raw materials used for the construction and maintenance of the national highway in USA, while 7 $\mathrm{x} 10^{6} \mathrm{MJ}$ energy were needed for the construction of $1 \mathrm{~km}$ long standard dual lane asphalt pavement.

In our country, the asphalt pavement material basically uses the traditional hot mix asphalt mixture, the material temperature is up to 150-180, not only to consume a lot of energy, but also emit a lot of greenhouse gases and other harmful gases in the process of production and construction. According to the production status of our country, the hot mix of asphalt mixture will produce $9 \times 10^{5}$ ton $\mathrm{CO} 2$, according to an average of $10 \mathrm{~km}$ distance, transportation equipment will discharge about 4 x 104t CO2, only the production, transport emissions of CO2, is can be filled with more than 20000 Olympic will special swimming pool.

In our country, the field of asphalt pavement construction, the technology of low carbon and environmental protection with features of asphalt pavement should be gradually popularized. However, due to the lack of detailed quantitative analysis of the greenhouse gas emissions in the process of asphalt pavement construction, the development and application of low carbon environmental protection technology of asphalt pavement is not obvious, and the theoretical basis is not sufficient. Therefore, it is not enough to establish a real sense of low carbon environmental protection asphalt pavement construction model currently.

\section{Research progress home and abroad}

\subsection{Foreign research status}

In July 15, 2009, the United Kingdom announced a detailed "British low carbon transformation" strategic plan to release the first annual carbon emissions report in the carbon budget system. The United States announced the use of "cap and trade system" to achieve greenhouse gas emission reduction targets. Japan has announced a long-term goal of reducing emissions: the medium-term

\footnotetext{
Introduction: ${ }^{1}$ Yangning, male(1972-), Vice President of Nanjing Communications Institute of Technology, Senior Engineer, majoring in Highway Engineering.

2 Chendongxiang,male(1977-),Associate professor,majoring in Traffic energy saving and emission reduction and environmental engineering

${ }^{3}$ Chenjin, female (1980_ ) Postdoctor, majoring in Traffic energy saving and emission reduction and environmental engineering
} 
goal, promised to cut emissions by 20\% in 2020 than in 1990; the long-term target for 2050, the CO2 emissions to cut $60 \%-80 \%$. Foreign scholars have carried out the research on how to measure the carbon emissions, Lenten and Weber has established assessment model for quantitative analysis in greenhouse gas emissions in Australia, Germany, France, Holland and other countries ${ }^{[1,2]}$.

For carbon emissions, factor decomposition method was used internationall . Ang B W decomposes industrial sector carbon emissions into economic growth impact, product structure and energy use efficiency impact factors[3]; Shyama divided the decomposition of carbon emissions into GDP three factors, industrial structure, energy intensity and energy carbon emissions[4]; Shyama[5] will break down the carbon emissions of India into four factors such as GDP, the impact of industrial structure, energy intensity and the carbon emissions[6]; Gipek Tunô divided into five factors such as economic growth effect, structure effect, energy utilization efficiency, energy was affected by kinds and the energy carbon emission coefficient[7].

\subsection{Domestic research status}

Compared with the carbon emissions from foreign countries, there is no official statistics on the carbon emissions. The carbon emissions data used by the academic circles are obtained by estimating. The carbon emissions of asphalt pavement in our country is still in its initial stage, the relevant research literature is not much. Chui-Te used life cycle inventory analysis (LCI) to study the environmental impact of recycled materials in asphalt pavement repair engineering, and to reduce the use of asphalt and reduce the production and construction of asphalt mixture.

\section{Problems to be solved}

\subsection{Investigation of energy consumption and greenhouse gas emissions of asphalt mixture and its influencing factors}

The existing production and construction process of asphalt mixture, as well as the current domestic and international asphalt mixture production and other key data indicators were collected through the research of domestic and foreign materials, as well as the actual engineering survey to investigate influence factors of energy consumption and greenhouse gas emissions of asphalt mixture.

(1) Analysis on production and construction process of asphalt mixture

(2) Energy consumption and greenhouse gas emissions types and its characteristics

(3) Analysis of factors affecting the energy consumption in asphalt mixture

(4) Analysis of factors affecting greenhouse gas emissions in asphalt mixture

\subsection{Study on quantitative analysis system of asphalt mixture and greenhouse gas emissions}

According to the influencing factors and the quantitative analysis of asphalt mixture and greenhouse gas emissions, a quantitative analysis model of the greenhouse gas emissions of asphalt mixture is established to analyze greenhouse gas emissions sources and categories.

(1) Source and category analysis of greenhouse gas emissions of asphalt mixture;

(2) Quantitative analysis of greenhouse gas emissions from the production of asphalt and stone;

(3) Quantitative analysis of greenhouse gas emissions in the mixing production of asphalt mixture;

(4) Quantitative analysis of greenhouse gas emissions in the transportation of asphalt mixture;

\subsection{Study on the measurement and monitoring method of the construction period in warm mixed asphalt mixture}

The greenhouse gas emission standard of hot mix asphalt mixture is put forward to study the effect of the greenhouse gas emissions in asphalt mixture.

(1) Base level of greenhouse gas emission in asphalt mixture (hot mix asphalt mixture) 
(2) Characteristics of production and construction technology of warm mix asphalt mixture;

(3) Energy consumption analysis of warm mix asphalt mixture

(4) Quantitative analysis of greenhouse gas emissions of asphalt mixture

(5) Measurement and monitoring method for energy saving and emission reduction of warm mix asphalt mixture.

\subsection{Practice and application of the method for reducing the emission of warm mix asphalt}

The greenhouse gas emissions from the project construction process is calculated by using the method of greenhouse gas measurement and monitoring.

(1) Application project of warm mix asphalt

(2) Calculation of energy consumption of warm mix asphalt mixture

(3) Measurement of greenhouse gas emissions of warm mix asphalt mixture

(4) Evaluation of energy saving and emission reduction effect of warm mix asphalt mixture

(5) Suggestion on reducing the temperature of warm mix asphalt mixture

\section{Conclusion}

The research on the key link of the greenhouse gas emissions of asphalt mixture, the quantitative analysis system of greenhouse gas emissions, and the research of the corresponding low carbon measure and technology are still blank. Therefore, systematic study is needed to develop a method for the measurement of greenhouse gas emission reduction of asphalt mixture, to analyze the sources of greenhouse gas emissions during the construction process of asphalt mixture, to establish a quantitative analysis system for the greenhouse gas emissions of asphalt mixture, and to carry out the performance of the asphalt mixture road with energy saving and emission reduction.

\section{Reference}

[1] Lenten M. Primary Energy and Greenhouse Gases Embodied in Australian Final Consumption: an Input-output Analysis [J]. Energy Policy, 1998,26(6).

[2] Weber C, Petrels A. Modeling Lifestyle Effects on Energy Demand and Related Emissions [J]. Energy Policy. 2000(28).

[3] Ang B W. Decomposition Analysis for Policymaking in Energy[J]. Which Is the Preferred Methods Energy Policy ,2004(32).

[4] Shyamal Paula1 Rabindra Nash Bhattacharya. $\mathrm{CO}_{2}$ Emission from Energy Use in India[J]. A Decomposition Analysis Energy Policy, 2004(32).

[5] GIpek TunÔ,Türüt2A.1k Serap,Elif Akbostanc1. A Decomposition Analysis of $\mathrm{CO}_{2}$ Emissions from Energy Use[J]. Turkish Case Energy Policy, 2009(37).

[6] Yue H, Bird R, Bell M. A comparative study of the emissions by road maintenance works and the disrupted traffic using life cycle assessment and micro-simulation[J].Transportation Research PartD: Transport and Environment,2009,14(3).

[7] Raja Chowdhury, Defne Apul, Tim Fry. A Life Cycle Based Environmental Impacts Assessment of Construction Materials Used in Road Construction[J]. Resources, Conservation and Recycling, 2010,54(4). 